\title{
Microwave-assisted asymmetric Diels-Alder reaction using chiral auxiliaries derived from biomass
}

\author{
Ariel M. Sarotti, Rolando A. Spanevello, and Alejandra G. Suárez* \\ Instituto de Química Rosario, Facultad de Ciencias Bioquímicas y Farmacéuticas - Universidad \\ Nacional de Rosario-CONICET, Suipacha 531, S2002LRK Rosario, Argentina \\ E-mail:suarez@iquir-conicet.gov.ar
}

\section{Dedicated to Professors Manuel González Sierra, Rita M. H. de Rossi, Julio Podestá and Oscar Giordano for their outstanding contribution to organic chemistry in Argentina}

\begin{abstract}
Microwave-assisted asymmetric Diels-Alder reactions using levoglucosenone-derived chiral auxiliaries have been investigated. The cycloaddition reaction between the corresponding chiral acrylate and cyclopentadiene showed important rate enhancements under microwave irradiation compared to conventional heating conditions, whereas the yields and diastereoselectivities were not significantly affected.
\end{abstract}

Keywords: Microwaves, Diels-Alder, asymmetric synthesis, levoglucosenone, acrylates

\section{Introduction}

The Diels-Alder reaction has proven to be an exceptionally powerful method for carbon-carbon bond forming reactions in the synthesis of natural products and novel structures of both fundamental and applied interest. Indeed, in this process the simultaneous creation of two new $\mathrm{C}-\mathrm{C}$ bonds is coupled with the possibility of regio- and stereo-control of the newly formed sixmembered ring. ${ }^{1}$

As part of our program on the pyrolytic conversion of biomass into useful chemicals, we have been concerned with the synthetic application of levoglucosenone (1,6-anhydro-3,4dideoxy- $\beta$ - $D$-glycero-hex-3-enopyranos-2-ulose) $\mathbf{1}$ as a chiral building block for the development of new tools for asymmetric synthesis. Conventional pyrolysis of cellulosecontaining materials such as waste paper is typically used to generate $\mathbf{1},{ }^{2,3}$ but microwave (MW) irradiation of microcrystalline cellulose is also effective. ${ }^{4}$ Recently, we have reported the design and synthesis of alcohols 2-6 derived from levoglucosenone (Scheme 1) and their use as chiral inductors in asymmetric Diels-Alder reactions of the corresponding acrylate with 
cyclopentadiene yielding the products with up to $98 \%$ diastereomeric excess in the presence of Lewis acids. $^{5}$

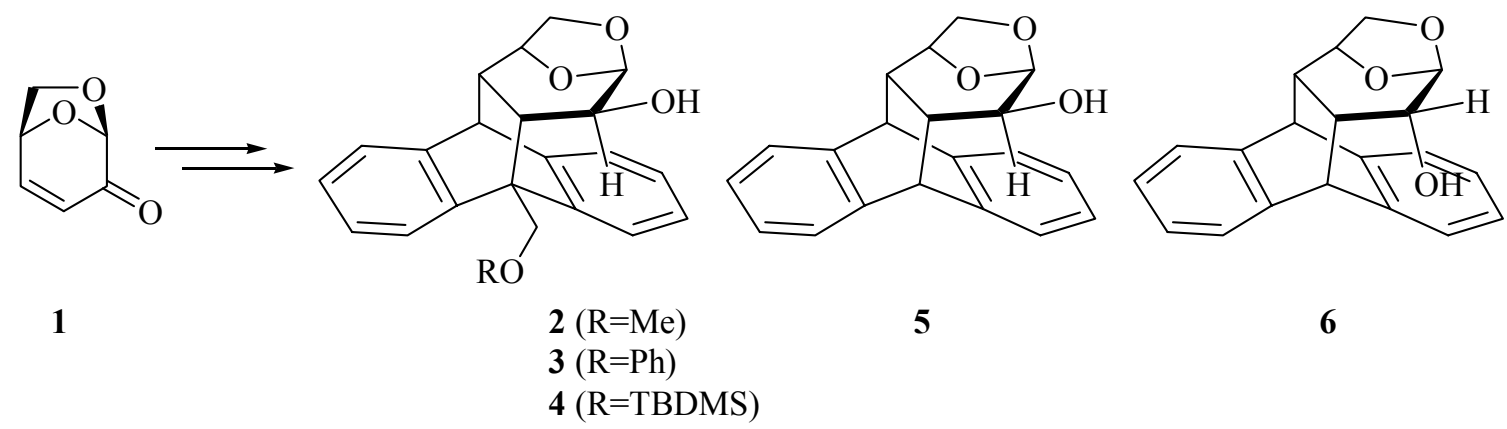

\section{Scheme 1}

In general non-catalyzed cycloaddition reactions do not afford good yields and selectivities of products. However, in our case the thermal Diels-Alder reactions produced the desired cycloadducts in very good yields (86-96\%) with an inversion of the endo selectivity compared to the catalyzed reactions. ${ }^{5}$ The best diastereo- (endo/exo, $\sim 72: 28$ ) and $\pi$-facial selectivities (up to $76 \%$ d.e.) were achieved at room temperature with the expected increase in reaction times (48-56 h). As the non-catalyzed Diels-Alder reactions needed long reaction times, we considered the use of a MW assisted procedure to improve the outcome of these reactions. ${ }^{6}$ This approach would save energy by shortening the reaction time and also by making the overall process more efficient and sustainable. We present herein the use of MW assisted Diels-Alder reaction of chiral acrylates derived from levoglucosenone with cyclopentadiene. The interest in this research is focused not only on the possibility to reduce reaction times, but also to evaluate the selectivity of the asymmetric process under MW irradiation which is of great synthetic and industrial significance.

\section{Results and Discussion}

In order to test the effectiveness of the chiral inductors 2-6 in asymmetric Diels-Alder reaction under MW irradiation we prepared the acrylates 7-11 according to the published procedures. ${ }^{5}$ The acylation step was easily performed in good yields by reaction of acryloyl chloride with the corresponding alcohol in the presence of triethylamine at $0{ }^{\circ} \mathrm{C}$. Cycloaddition reactions of acrylates 7-11 with cyclopentadiene were carried out under MW irradiation, yielding the four isomeric products depicted in Scheme 2.

To make a systematic study of the different factors involved in these cycloaddition reactions, we first tested the role of the solvent as it can be a crucial factor in the outcome of the reaction. The selection of solvents was made considering a wide range of MW energy absorption capacity. 
We used as a model reaction the cycloaddition of acrylate 7 with cyclopentadiene using a $300 \mathrm{~W}$ irradiation power. The use of hexane or THF did not produce the desired products since extensive polymerization of the cyclopentadiene took place under these conditions. However, after only $5 \mathrm{~min}$ of $\mathrm{MW}$ irradiation at $300 \mathrm{~W}$, total conversion of the acrylate into the expected cycloadducts was observed using toluene $(\mathrm{PhMe})$, ethanol $(\mathrm{EtOH})$ or 1,1,1-trichloroethane (TCE) as solvents. Following these encouraging results, we next evaluated the cycloaddition reaction of several chiral acrylates using the same MW irradiation conditions (Table 1).

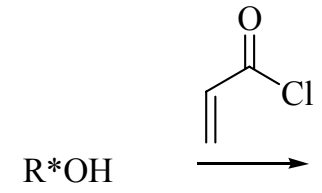

2-6<smiles>C=CC(=O)OCC</smiles>

$7(\mathrm{R} * \mathrm{OH}=\mathbf{2})$

$8(\mathrm{R} * \mathrm{OH}=\mathbf{3})$

$9(\mathrm{R} * \mathrm{OH}=4)$

$10(\mathrm{R} * \mathrm{OH}=\mathbf{5})$

$11(\mathrm{R} * \mathrm{OH}=\mathbf{6})$
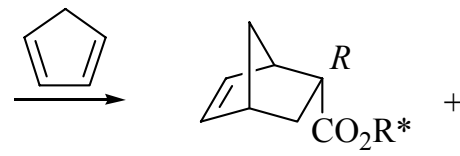

12a

$13 a$

$14 a$

$15 \mathbf{a}$

$16 \mathrm{a}$

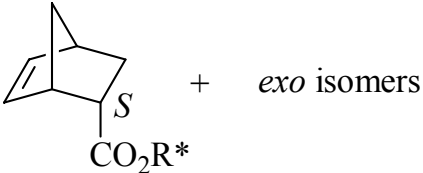

12b

$13 b$

14b

$15 b$

$16 \mathrm{~b}$ 12c,d

$13 c, d$

14c,d

$15 \mathrm{c}, \mathrm{d}$

16c,d

\section{Scheme 2}

Table 1. MW assisted Diels-Alder reaction between chiral acrylates 7-11 and cyclopentadiene. General conditions: $300 \mathrm{~W}, 5$ min

\begin{tabular}{llllll}
\hline Entry & Chiral Acrylate & Solvent & Yield $(\%)$ & $\begin{array}{l}\text { Ratio } \\
\text { endo/exo }\end{array}$ & $\begin{array}{c}\text { Ratio } \\
\text { endo } S / R\end{array}$ \\
\hline 1 & $\mathbf{7}$ & PhMe & 98 & $66: 34$ & $74: 26$ \\
2 & $\mathbf{7}$ & EtOH & 97 & $72: 28$ & $69: 31$ \\
3 & $\mathbf{7}$ & TCE & 93 & $66: 34$ & $71: 29$ \\
4 & $\mathbf{8}$ & PhMe & 99 & $67: 33$ & $73: 27$ \\
5 & $\mathbf{8}$ & EtOH & 79 & $71: 29$ & $73: 27$ \\
6 & $\mathbf{8}$ & TCE & 94 & $71: 29$ & $72: 28$ \\
7 & $\mathbf{9}$ & PhMe & 98 & $70: 30$ & $80: 20$ \\
8 & $\mathbf{9}$ & EtOH & 94 & $73: 27$ & $76: 24$ \\
9 & $\mathbf{9}$ & TCE & 90 & $66: 34$ & $76: 24$ \\
10 & $\mathbf{1 0}$ & PhMe & 98 & $70: 30$ & $55: 45$ \\
11 & $\mathbf{1 0}$ & EtOH & 98 & $75: 25$ & $51: 49$ \\
12 & $\mathbf{1 0}$ & TCE & 98 & $69: 31$ & $53: 47$ \\
13 & $\mathbf{1 1}$ & PhMe & 89 & $71: 29$ & $31: 69$ \\
14 & $\mathbf{1 1}$ & EtOH & 91 & $70: 30$ & $32: 68$ \\
15 & $\mathbf{1 1}$ & TCE & 90 & $64: 36$ & $35: 65$ \\
\hline
\end{tabular}


The experimental data shown in Table 1 reveal that excellent yields were obtained in all cases. The stereochemical outcome of the cycloadditions showed little dependence on the solvent employed, although best endo/exo ratios were observed in EtOH whereas PhMe afforded the highest $\pi$-facial selectivities. Accordingly, further investigation was made using $\mathrm{EtOH}$ and $\mathrm{PhMe}$ as solvents.

Given the impressive reduction in reaction time when using MW irradiation (from 48-56 h to $5 \mathrm{~min}$ ), a more comprehensive study directed toward finding optimal reaction conditions seemed to be appropriate. At this stage, there was a presumed relationship between the reaction temperature with the endo/exo and endo $R / S$ ratios. We next investigated the effect of the irradiation time in the reaction of acrylate 7 and cyclopentadiene, with a power-controlled program at $300 \mathrm{~W}$ (Table 2).

Table 2. MW assisted Diels-Alder reactions between chiral acrylate 7 and cyclopentadiene. General conditions: PhMe, $300 \mathrm{~W}$

\begin{tabular}{lllllll}
\hline Entry & $\begin{array}{l}\text { Time } \\
(\mathrm{sec})\end{array}$ & $\mathrm{T}\left({ }^{\circ} \mathrm{C}\right)^{\mathrm{a}}$ & Conv. & Yield (\%) & $\begin{array}{l}\text { Ratio } \\
\text { endo/exo }\end{array}$ & $\begin{array}{l}\text { Ratio } \\
\text { endo } S / R\end{array}$ \\
\hline 1 & 75 & 68 & 44 & 42 & $70: 30$ & $80: 20$ \\
2 & 150 & 103 & 87 & 81 & $67: 33$ & $75: 25$ \\
3 & 225 & 128 & 95 & 91 & $67: 33$ & $74: 26$ \\
4 & 300 & 140 & 100 & 98 & $66: 34$ & $74: 26$ \\
\hline
\end{tabular}

${ }^{\mathrm{a}}$ Maximum temperature reached at the indicated time.

These experimental results indicate that there is a slight increase in selectivity at lower temperatures. For this reason, we considered diminishing the MW irradiation power, the reduction in reaction temperature obtained thereby, could increase the selectivity ratios. Table 3 shows the results obtained in a temperature-controlled program at $70{ }^{\circ} \mathrm{C}$, which is the lowest temperature achieved employing $\mathrm{PhMe}$ or EtOH as solvents (MW irradiation power was approximately $5 \mathrm{~W}$ for $\mathrm{PhMe}$ and $1 \mathrm{~W}$ for $\mathrm{EtOH}$ ). At this temperature, a longer irradiation time (25 min) was needed for total consumption of the starting material. 
Table 3. MW assisted Diels-Alder reactions between chiral acrylates 7-11 and cyclopentadiene. General conditions: $70^{\circ} \mathrm{C}, 25 \mathrm{~min}$.

\begin{tabular}{llllll}
\hline Entry & Chiral Acrylate & Solvent & Yield (\%) & $\begin{array}{l}\text { Ratio } \\
\text { endo/exo }\end{array}$ & $\begin{array}{l}\text { Ratio } \\
\text { endo S/R }\end{array}$ \\
\hline 1 & $\mathbf{7}$ & PhMe & 92 & $69: 31$ & $78: 22$ \\
2 & $\mathbf{7}$ & EtOH & 99 & $75: 25$ & $71: 29$ \\
3 & $\mathbf{8}$ & PhMe & 97 & $71: 29$ & $80: 20$ \\
4 & $\mathbf{8}$ & EtOH & 96 & $77: 23$ & $76: 24$ \\
5 & $\mathbf{9}$ & PhMe & 91 & $69: 31$ & $83: 17$ \\
6 & $\mathbf{9}$ & EtOH & 97 & $78: 22$ & $81: 19$ \\
7 & $\mathbf{1 0}$ & PhMe & 92 & $73: 27$ & $57: 43$ \\
8 & $\mathbf{1 0}$ & EtOH & 89 & $79: 21$ & $53: 47$ \\
9 & $\mathbf{1 1}$ & PhMe & 86 & $78: 22$ & $30: 70$ \\
10 & $\mathbf{1 1}$ & EtOH & 95 & $75: 25$ & $31: 69$ \\
\hline
\end{tabular}

As shown in Table 3, the reduction in reaction temperature gave a slight improvement in selectivity whereas the overall yields were excellent in all cases. As a general trend, EtOH gave better endo/exo ratios and $\mathrm{PhMe}$ was the best in terms of facial selectivity.

From the experimental results collected in Tables 1 and 3, it can be observed that the power of the MW irradiation had an important effect on the reaction rate. Comparing the results obtained under thermal conditions vs MW irradiation it was evident that the latter produced an impressive increment in the reaction rates without significant changes in yields and selectivities. Finally, it is noteworthy to mention that none of the cycloaddition reactions reported in this study showed a retro Diels-Alder path, as was demonstrated to be the case in other MW accelerated Diels-Alder reactions. ${ }^{7}$

\section{Conclusions}

We have shown the impact of MW activation in asymmetric Diels-Alder reactions of chiral acrylates derived from levoglucosenone and cyclopentadiene. After extensive investigation, we found the optimal reaction conditions ( $\mathrm{PhMe}$ or $\mathrm{EtOH}, 70{ }^{\circ} \mathrm{C}, 25 \mathrm{~min}$ ) in terms of yield and selectivity. The desired products were isolated in excellent yields, and most importantly, the reaction time was dramatically shortened without loss of selectivity.

\section{Experimental Section}

General. The MW heating was performed in a CEM-Discover ${ }^{\circledR}$ System using a $10 \mathrm{~mL}$ pressurerated reaction vials. HPLC analyses were performed with a chromatograph Varian ProStar 
equipped with UV-V detector ProStar 320 at $270 \mathrm{~nm}$, using a Beckman C-18, $25 \mathrm{~cm}$ column. Acetonitrile and water HPLC grade were used as eluents in a mixture 80:20, respectively. Flow rate was $1 \mathrm{~mL} / \mathrm{min}$. Nuclear magnetic resonance spectra were recorded on a Bruker Avance-300 DPX spectrometer with tetramethylsilane as internal standard and deuterochloroform as solvent. The reactions were monitored by thin layer chromatography carried out on $0.25 \mathrm{~mm}$ E. Merck silica gel plates $\left(60 \mathrm{~F}_{254}\right)$ that were developed using UV light and $p$-anisaldehyde-sulfuric acidacetic acid with subsequent heating. Flash column chromatography was performed using Merck silica gel $60 \mathrm{H}$, by gradient elution created by mixtures of hexanes and increasing amounts of ethyl acetate. For complete characterization data of products 12a-d, 13a-d and 14a-d see reference 5(a), for products 15a-d and 16a-d, see reference 5(c).

\section{General procedure for the cycloaddition reaction of acrylates (7-11) and cyclopentadiene under MW irradiation}

The corresponding acrylate $(0.1 \mathrm{mmol})$ and cyclopentadiene $(1 \mathrm{mmol})$ were placed in a $10 \mathrm{~mL}$ vial, dissolved in $4 \mathrm{~mL}$ of the suitable solvent, and heated for the time and $\mathrm{MW}$ irradiation power indicated in Tables 1-3. The solvent was then evaporated under reduced pressure and the residue was purified by flash chromatography to separate the excess of diene; the adducts were collected together to obtain an accurate yield. Endo/exo and $R / S$ ratios were determined by HPLC, ${ }^{1} \mathrm{H}$ and ${ }^{13} \mathrm{C}$ NMR.

\section{Acknowledgements}

This research was supported by grants from Universidad Nacional de Rosario, Consejo Nacional de Investigaciones Científicas y Técnicas (CONICET), Agencia Nacional de Promoción Científica y Tecnológica (ANPCyT) and Secretaría de Estado de Ciencia, Tecnología e Innovación de la Provincia de Santa Fe.

\section{References}

1. Fringuelli, F.; Taticchi, A. The Diels-Alder Reaction. Selected Practical Methods; John Wiley \& Sons: New York, 2002. (b) Fleming, I. Pericyclic Reactions; Oxford University Press Inc.: New York, 1999. (c) Nicolaou, K. C.; Snyder, S. A.; Montagnon, T.; Vassilikogiannakis, G. Angew. Chem., Int. Ed. 2002, 41, 1668.

2. Witczak, Z. J. Levoglucosenone and Levoglucosans: Chemistry and Applications; ATL: Mount Prospect, 1994. (b) Witczak, Z. J.; Tatsuta, K.; Carbohydrate Synthons in Natural Products Chemistry. Synthesis, Functionalization, and Applications; ACS Symposium Series; American Chemical Society: Washington, D.C., 2003.

3. Swenton, J. S.; Freskos, J. N.; Dalidowicz, P.; Kerns, M. L. J. Org. Chem. 1996, 61, 459. 
4. Sarotti, A. M.; Spanevello, R. A.; Suárez, A. G. Green Chem. 2007, 9, 1137.

5. Sarotti, A. M.; Spanevello, R. A.; Suárez, A. G. Tetrahedron 2009, 65, 3502. (b) Sarotti, A. M.; Fernández, I.; Spanevello, R. A.; Sierra, M. A.; Suárez, A. G. Org. Lett. 2008, 10, 3389. (c) Sarotti, A. M.; Spanevello, R. A.; Duhayon, C.; Tuchagues, J.-P.; Suárez, A. G. Tetrahedron 2007, 63, 241. (d) Sarotti, A. M.; Spanevello, R. A.; Suárez, A. G. Org. Lett. 2006, 8, 1487.

6. Hayes, B. L. Microwave Synthesis. Chemistry at the Speed of Light; CEM Publishing: Matthews, NC, 2002; Chapter 4. (b) Martínez Palau, R. Química en Microondas; CEM Publishing: Matthews, NC, 2006; Chapter 3. (c) Kappe, C. O. Angew. Chem., Int. Ed. 2004, 43, 6250. (d) Lidström, P.; Tierney, J.; Wathey, B.; Westman, J. Tetrahedron 2001, 57, 9225. (e) de la Hoz, A.; Díaz-Ortis, A.; Moreno, A.; Langa, F. Eur. J. Org. Chem. 2000, 3659.

7. Sarotti A. M.; Joullié, M. M.; Spanevello, R. A.; Suárez, A. G. Org. Lett. 2006, 8, 5561. 